\title{
Impact of exacerbation on the errors of inhaler techniques in COPD patients
}

\author{
Duangjai Duangrithi ${ }^{1 *}$, Kaitsuda Saiprom ${ }^{2}$, Jittra SaeTew ${ }^{2}$, Yahya Sa-u ${ }^{2}$ \\ ${ }^{1}$ Department of Pharmaceutical care, Faculty of Pharmacy, Rangsit University, 52/347 Muang-Ake Paholyothin Road, Lak Hok District, Mueang Pathum \\ Thani, Pathumtani, Thailand. ${ }^{2}$ Faculty of Pharmacy, Rangsit University, 52/347 Muang-Ake Paholyothin Road, Lak Hok District, Mueang Pathum Thani, \\ Pathumtani, Thailand.
}

\section{ARTICLE INFO}

Article history:

Received on: 14/11/2016

Accepted on: 08/02/2017

Available online: $30 / 05 / 2017$

\section{Key words:}

Inhaler technique, COPD, exacerbation, critical error.

\begin{abstract}
Identification of poor inhaler technique is vital for COPD management at time of hospital discharge and thereafter. This observational study aimed to determine the impact of exacerbation on the errors of inhaler techniques among COPD patients. The study was conducted in chest clinic at Central Chest Institute of Thailand. Patients having diagnosed of COPD for at least 1 year, treated with inhalation devices and attained inhaler technique training were eligible for study. Demographic and clinical characteristics were obtained and inhaler techniques were assessed. The error was classified as critical or noncritical regarding medication reaching the lungs. Among 143 patients, 27 had history of exacerbation. The median inhaler devices per patients were 2 similarly in both groups. The proportion of patients performing at least 1 critical error was significantly lower in those having history of exacerbation and using pMDI without spacer $(\mathrm{p}=0.020)$ while the proportion of patients performing at least 1 error was significantly higher in those with history of exacerbation $(p=0.014)$. History of exacerbation has no impact on inhaler technique except MDI without spacer. Continuing inhaler technique training and assessment are strongly recommended to sustain proper inhaler technique as well as increase quality of life and economic benefits.
\end{abstract}

\section{INTRODUCTION}

Chronic obstructive pulmonary diseases (COPD) is the major cause of chronic morbidity and will rank $7^{\text {th }}$ of global burden of diseases in 2030 (Bousquet and Khaltaev, 2007). The estimated prevalence of COPD are 4-20\% worldwide in adults over 40 years of age and $6.3 \%$ in Asian population (Bousquet and Khaltaev, 2007). Furthermore, it is the $4^{\text {th }}$ most common causes of hospitalization and most economic burden among chronic diseases in elderly patients (Bousquet and Khaltaev, 2007). Exacerbation of COPD is "an acute event characterized by a worsening of the patient's respiratory symptoms that is beyond normal day-to-day variations and leads to a change in medication" (Roisin and Vestbo, 2013). It accounts for two third

\footnotetext{
* Corresponding Author

Duangjai Duangrithi, Department of Pharmaceutical care, Faculty of Pharmacy, Rangsit University, Thailand. E-mail: djdr@ hotmail.com
}

of the direct cost of COPD (Anzueto, 2010). Frequent exacerbations negatively impact on health aspects: lung function, exercise capacity, quality of life, morbidity and mortality (Anzueto, 2010) and socioeconomic aspects: inhaler and hospitalization cost (Capstick and Clifton, 2012). Therefore, the outcome of treatment is to minimize the impact of current exacerbation and to prevent the development of subsequent exacerbations (Roisin and Vestbo, 2013). Several treatment modalities are proposed to prevent exacerbation including the correct use of inhaler devices (Roisin and Vestbo, 2013).

However, inhaler handling error is common among COPD patients (Melani et al., 2011) and the cooperation rate of inhaler therapy is much lower than other chronic diseases (Agh and Meszaros, 2012). There were $75 \%$ of COPD patients performed at least 1 critical error of inhaler handling leading to little or no medication reaching the lungs, (Pothirat et al., 2015) and even higher to $90 \%$ in those with exacerbation (Ahmad et al., 2013) but it could be reduced to $25 \%$ after training (Pothirat et al., 2015). 
However, COPD patients experiencing this life threatening condition had a better response to education and management plan (Farkas et al., 2011). Therefore, identification of poor inhaler technique becomes an essential part of the COPD management especially, re-assessment at the time of hospital discharge and $4-6$ weeks later as recommended by Global Initiative for Chronic Obstructive Lung Disease (GOLD) 2013 (Roisin and Vestbo, 2013). But sustaining correct inhaler technique after exacerbation is still controversy (Press et al., 2012). This study aimed to determine the impact of exacerbation on the errors of inhaler techniques among COPD patients.

\section{MATERIAL AND METHODS}

This observational study was conducted in chest clinic at Central Chest Institute of Thailand. The study was approved by the Institute ethics committee. The previous study showed that $75 \%$ of COPD patients performed at least 1 error across 4 different types of inhaler devices (Pothirat et al., 2015). In our study, at least 5 types of prescribed devices were expected then patients performed at least 1 error was estimated to be $90 \%$ with a $95 \%$ confidence interval and the precision to be within $5 \%$ of the true value. In order to compare inhaler techniques between patients with and without exacerbation, the estimated ratio of was based on $21 \%$ hospitalization rate among COPD patients (Bollu et al., 2013). Therefore, the sample size of at least 138 patients with the ratio of 1:4 for patients with and without exacerbation was required for this study.

\section{Study participants}

Patients having diagnosed as COPD for at least 1 year, treated with inhalation devices, attained inhaler technique training by pharmacists either at regular appointment or before hospital discharge were eligible for study. Exclusion criteria were having co-morbidity of cardiovascular diseases, asthma or lung cancer and unable to co-operate in assessment of inhaler devices. Study information was provided by verbal and participant information sheets to all patients before obtaining written informed consent.

\section{Study Procedures}

Face-to-face interview was conducted to obtain demographic characteristics while clinical characteristics were obtained from medical records. Patients were asked to demonstrate inhaler technique for each currently prescribed inhalers containing placebo and were assessed using inhaler technique checklists (Allen, 1997; Ho et al., 2004; Batterink et al., 2012).

\section{Statistical Methods}

Categorical variables were summarized as frequencies and percentages, and then analyzed using the chi square test or the Fisher's exact test. Continuous variables were summarized as mean and standard deviation or median and interquartile range (IQR) values and compared using t-test or the Mann-Whitney Utest where appropriate. The multiple logistic regression was performed on the variables with significant differences between patients with and without exacerbation using overall errors as the dependence variable. All tests for significance were two-sided and $\mathrm{p}<0.05$ was considered statistical significance.

\section{Definitions}

GOLD classification (Roisin and Vestbo, 2013): the spirometric classification of airflow limitation: GOLD 1, mild; GOLD 2, moderate; GOLD 3, severe; and GOLD 4, very severe.

Critical error (Batterink et al., 2012; Allen, 1997; Ho et al., 2004): step of which incorrect performance would lead to little or no medication reaching the lungs.

Multiple devices: prescribed inhaler $\geq 2$ devices for each patient.

\section{RESULTS}

\section{Socio-demography}

The totals of 143 patients were enrolled in the study. There were 27 patients $(23.28 \%$ ) with history of exacerbation. Of these, 10 patients had frequent exacerbations ( 2 exacerbations per year). Majority of patients were male similarly in both groups (92.6\% vs $93.10 \%, \mathrm{p}=1.000)$. They were elderly and those with history of exacerbation were slightly younger $($ median $(\mathrm{IQR})=$ 69.00 years $(62.00-76.00)$ vs 71.50 years $(65.00-77.00), \mathrm{p}=0.295)$. Most of them were married ( $85.20 \%$ vs $76.70 \%, \mathrm{p}=0.337)$, having low education level $(73.10 \%$ vs $71.40 \%, \mathrm{p}=0.869)$ and low income $(80.80 \%$ vs $70.30 \%, \mathrm{p}=0.292)$ similarly in both groups. Disease severity was significantly different between both groups $(\mathrm{p}=0.010)$ and the proportion of patients with severe disease (GOLD 3 and 4) was significantly higher in exacerbation group $(39.60 \%$ vs $70.30 \%, \mathrm{p}=0.004)$ (table 1$)$.

\section{Inhaler devices}

There were 5 different types of prescribed inhaler devices: pressurized metered dose inhaler (pMDI) with and without spacer, turbuhaler, accuhaler and handihaler. The median prescribed inhaler devices per patients (IQR) were 2 similarly in both groups $(2(2.00-2.00)$ vs $2(2.00-2.50), \mathrm{p}=0.270)$. Proportion of patients using multiple devices was significantly higher in patients with history of exacerbation $(78.40 \%$ vs $100.00 \%$, $\mathrm{p}=0.004)$. The pMDI without spacer and accuhaler were the most common devices prescribed in both groups. The latter had significantly higher proportion in patients with history of exacerbation $(85.20 \%$ vs $64.70 \%, \mathrm{p}=0.039)$ while turbuhaler was the less common similarly in both groups $(3.70 \%$ vs $7.76 \%$, $\mathrm{p}=0.687$ ) (figure 1). Long acting $\mathrm{B}_{2}$ agonists and inhaled corticosteroids were the most common prescribed inhalers with the significantly higher proportions in exacerbation group $(\mathrm{p}=0.004$ and $\mathrm{p}=0.014$ ) (figure 2).

Generally, proportion of patients performing at least 1 error was significantly higher in those with history of exacerbation $(100 \%$ vs $81.90 \%, \mathrm{p}=0.014)$ while proportion of patients performing at least 1 critical error was similar in both groups 
(59.30\% vs $53.40 \%, \mathrm{p}=0.585)$. However, among those using pMDI without spacer, proportion of patients performing at least 1 critical error was significantly lower in exacerbation group $(4.80 \%$ vs $29.20 \%, \mathrm{p}=0.020)$. Patients using turbuhaler showed the highest error and critical error rates in both groups (table 2) and the step of loading a dose was the most common mistake (table 3). After controlling for confounders, critical error of pMDI without spacer was 0.04 times lower $(95 \% \mathrm{CI}=0.003-0.60, \mathrm{p}=0.020)$ and number of prescribed medications was 10.85 times higher in patients with history of exacerbation $(95 \% \mathrm{CI}=1.69-69.51, \mathrm{p}=0.012)$.

Table 1: Demographics and clinical characteristics of COPD patients.

\begin{tabular}{|c|c|c|c|c|c|c|}
\hline \multirow[t]{2}{*}{ Variables } & \multirow[b]{2}{*}{$\mathbf{n}$} & \multicolumn{4}{|c|}{ History of exacerbation } & \multirow{2}{*}{$\begin{array}{c}p \\
\text { value }\end{array}$} \\
\hline & & $\mathbf{n}$ & No n $(\%)$ & $\mathbf{n}$ & Yes n $(\%)$ & \\
\hline$\overline{\text { Male }}$ & 143 & 116 & $108(93.10)$ & 27 & $25(92.6)$ & 1.000 \\
\hline Age (year); median (IQR) & 143 & 116 & $71.50(65.00-77.00)$ & 27 & $69.00(62.00-76.00)$ & 0.295 \\
\hline Married & 143 & 116 & $89(76.70)$ & 27 & $23(85.20)$ & 0.337 \\
\hline Senior high school and lower; $\mathrm{n}(\%)$ & 117 & 91 & $65(71.40)$ & 26 & $19(73.10)$ & 0.869 \\
\hline Low income (<5000 bath) & 117 & 91 & $64(70.30)$ & 26 & $21(80.80)$ & 0.292 \\
\hline Smokers & 128 & 103 & & 25 & & 1.000 \\
\hline Current smokers & & & $6(5.80)$ & & $1(4.00)$ & \\
\hline Ex-smokers & & & $97(94.20)$ & & $24(96.00)$ & \\
\hline Duration of COPD (years) ; median (IQR) & 143 & 116 & $4.00(2.00-8.00)$ & 27 & $4.00(2.00-8.00)$ & 0.874 \\
\hline Severity & 143 & 116 & & 27 & & 0.010 \\
\hline GOLD 1 & & & $19(16.40)$ & & $3(11.10)$ & \\
\hline GOLD 2 & & & $51(44.00)$ & & $5(18.50)$ & \\
\hline GOLD 3 & & & $33(28.40)$ & & $12(44.40)$ & \\
\hline GOLD 4 & & & $13(11.20)$ & & $7(25.90)$ & \\
\hline Number of inhaler devices; median (IQR) & 143 & 116 & $2(2.00-2.00)$ & 27 & $2(2.00-2.50)$ & 0.270 \\
\hline
\end{tabular}

Table 2: Inhaler devices and at least 1 overall and critical error in COPD patients with and without history of exacerbation

\begin{tabular}{|c|c|c|c|c|c|c|c|c|c|c|}
\hline \multirow[t]{2}{*}{ Inhaler devices } & \multirow[b]{2}{*}{$\mathbf{n}$} & \multicolumn{3}{|c|}{ Overall errors } & \multirow[t]{2}{*}{ p value } & \multicolumn{4}{|c|}{ Critical errors } & \multirow[t]{2}{*}{ p value } \\
\hline & & no exacerbations & $\mathbf{n}$ & exacerbations & & $\mathbf{n}$ & no exacerbations & $\mathbf{n}$ & exacerbations & \\
\hline pMDI (n=93) & 72 & $53(73.60)$ & 21 & $17(81.00)$ & 0.493 & 72 & $21(29.20)$ & 21 & $1(4.80)$ & 0.020 \\
\hline pMDI with spacer $(\mathrm{n}=52)$ & 43 & $22(51.20)$ & 9 & $3(33.30)$ & 0.469 & 43 & $20(46.51)$ & 9 & $6(66.70)$ & 0.465 \\
\hline Turbuhaler $(\mathrm{n}=10)$ & 9 & $8(88.90)$ & 1 & $1(100.00)$ & 1.000 & 9 & $5(55.6)$ & 1 & $1(100.00)$ & 1.000 \\
\hline Accuhaler $(\mathrm{n}=98)$ & 75 & $56(74.40)$ & 23 & $18(78.30)$ & 0.726 & 75 & $35(46.70)$ & 23 & $15(65.20)$ & 0.119 \\
\hline Handihaler $(n=33)$ & 23 & $13(56.50)$ & 10 & $9(90.00)$ & 0.109 & 23 & $2(8.70)$ & 10 & $1(10.00)$ & 1.000 \\
\hline All devices $(n=143)$ & 116 & $95(81.90)$ & 27 & $27(100.00)$ & 0.014 & 116 & $62(53.40)$ & 27 & $16(59.30)$ & 0.585 \\
\hline
\end{tabular}

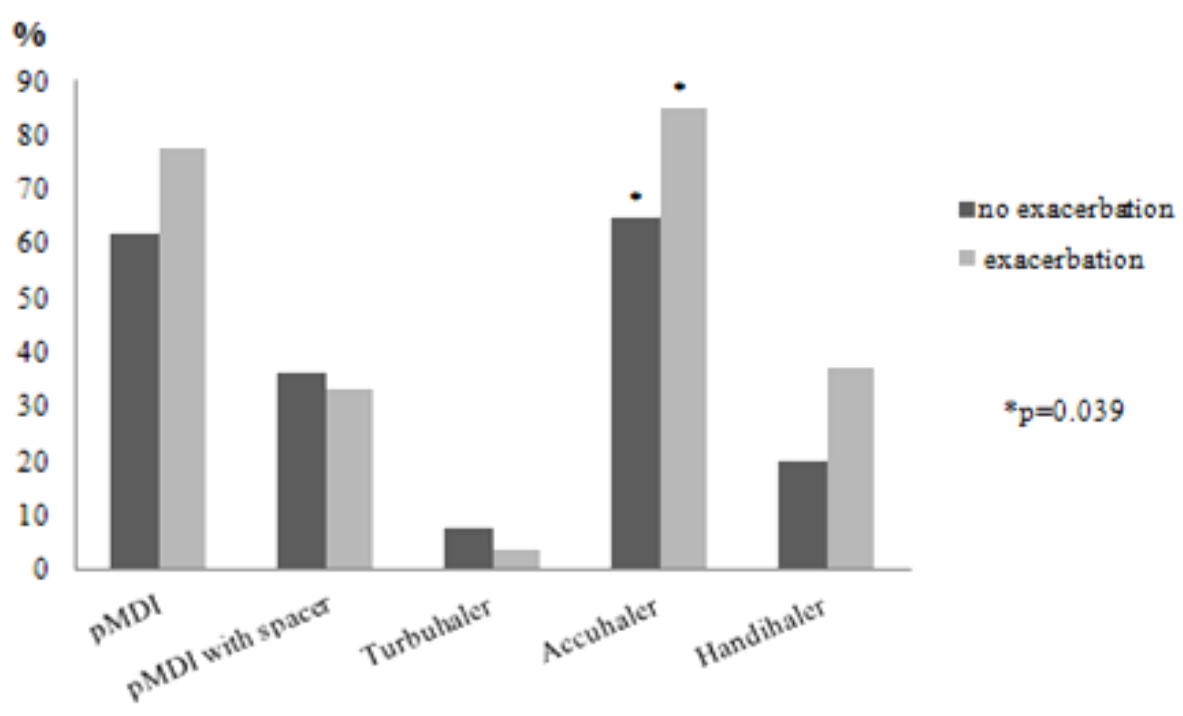

Fig. 1: Inhaler devices prescribed in COPD patients with and without history of exacerbation. 


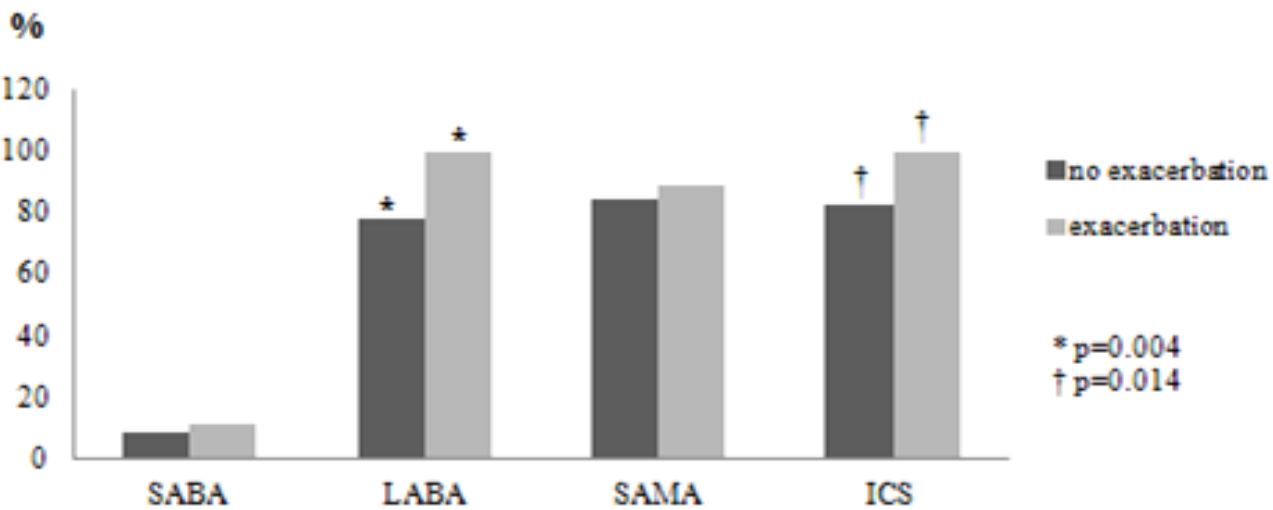

Fig. 2: Pharmacologic classifications of inhalers prescribed in COPD patients with and without history of exacerbation. (SABA: Short acting $B_{2}$ agonist, LABA: Long acting $B_{2}$ agonist, SAMA: Anticholinergic $+B_{2}$ agonist, ICS: inhaled corticosteroids)

Table 3: Incorrect steps of inhaler devices in COPD patients with and without history of exacerbation.

\begin{tabular}{|c|c|c|c|c|c|c|c|c|c|c|}
\hline \multirow[b]{2}{*}{ History of exacerbation } & \multicolumn{2}{|c|}{ pMDI $(n=72 / 21)$} & \multicolumn{2}{|c|}{$\begin{array}{c}\text { pMDI1 with spacer } \\
(n=42 / 9)\end{array}$} & \multicolumn{2}{|c|}{$\begin{array}{c}\text { Turbuhaler } \\
(n=9 / 1)\end{array}$} & \multicolumn{2}{|c|}{$\begin{array}{c}\text { Accuhaler } \\
(n=75 / 23)\end{array}$} & \multicolumn{2}{|c|}{$\begin{array}{l}\text { Handihaler } \\
(\mathrm{n}=23 / \mathbf{1 0})\end{array}$} \\
\hline & No & Yes & No & Yes & No & Yes & No & Yes & No & Yes \\
\hline Shake thoroughly* & $\begin{array}{c}20^{\mathrm{a}} \\
(27.80) \\
\end{array}$ & $\begin{array}{c}1^{\mathrm{a}} \\
(4.80) \\
\end{array}$ & $\begin{array}{c}16 \\
(38.10) \\
\end{array}$ & $\begin{array}{c}2 \\
(22.20) \\
\end{array}$ & NA & NA & NA & NA & NA & NA \\
\hline $\begin{array}{l}\begin{array}{l}\text { Remove capsule from blister and place in } \\
\text { chamber* }\end{array} \\
\end{array}$ & NA & NA & NA & NA & NA & NA & NA & NA & $\begin{array}{c}1 \\
(4.30)\end{array}$ & 0 \\
\hline $\begin{array}{l}\text { Hold in upright position or horizontally (and press } \\
\text { green piercing button in once and release) } *\end{array}$ & $\begin{array}{c}1 \\
(1.40)\end{array}$ & $\begin{array}{c}1 \\
(4.80)\end{array}$ & 0 & 0 & 0 & 0 & $14(18.70)$ & $\begin{array}{c}7 \\
(30.40)\end{array}$ & $\begin{array}{c}1 \\
(4.30)\end{array}$ & 0 \\
\hline Insert inhaler into spacer* & NA & NA & $\begin{array}{c}1 \\
(2.40) \\
\end{array}$ & 0 & NA & NA & NA & NA & NA & NA \\
\hline $\begin{array}{l}\text { Twisting grip to right and then back until click is } \\
\text { heard* }\end{array}$ & NA & NA & NA & NA & $\begin{array}{c}1 \\
(11.10) \\
\end{array}$ & $\begin{array}{c}1 \\
(100.00) \\
\end{array}$ & NA & NA & NA & NA \\
\hline $\begin{array}{l}\text { Open using thumb grip and load dose by sliding } \\
\text { lever until it clicks* }\end{array}$ & NA & NA & NA & NA & NA & NA & $\begin{array}{c}1 \\
(1.30) \\
\end{array}$ & $\begin{array}{c}1 \\
(4.30)\end{array}$ & NA & NA \\
\hline Breath out gently (away from mouthpiece) $*$ & $\begin{array}{c}33 \\
(45.80) \\
\end{array}$ & $\begin{array}{c}8 \\
(38.10) \\
\end{array}$ & $\begin{array}{c}26^{6} \\
(61.90) \\
\end{array}$ & $\begin{array}{c}1^{\mathrm{b}} \\
(11.10)\end{array}$ & $\begin{array}{c}5 \\
(55.60) \\
\end{array}$ & 0 & $20(26.70)$ & $\begin{array}{c}9 \\
(39.10)\end{array}$ & $\begin{array}{c}9 \\
39.10) \\
\end{array}$ & $\begin{array}{c}6 \\
(60.00) \\
\end{array}$ \\
\hline $\begin{array}{l}\text { Close lips on mouthpiece or hold } 3-4 \mathrm{~cm} \text {. away } \\
\text { from mouth }\end{array}$ & $\begin{array}{c}4 \\
(5.60) \\
\end{array}$ & 0 & $\begin{array}{c}2 \\
(4.80) \\
\end{array}$ & $\begin{array}{c}2 \\
(22.20)\end{array}$ & 0 & 0 & $\begin{array}{c}1 \\
(1.30)\end{array}$ & 0 & $\begin{array}{c}2 \\
(8.70)\end{array}$ & 0 \\
\hline $\begin{array}{l}\text { Press down firmly on canister once and/or breath in } \\
\text { slowly and deeply* }\end{array}$ & $\begin{array}{c}2 \\
(2.80) \\
\end{array}$ & 0 & $\begin{array}{c}1 \\
(2.40)\end{array}$ & $\begin{array}{c}1 \\
(11.10)\end{array}$ & NA & NA & $\begin{array}{c}1 \\
(1.30) \\
\end{array}$ & 0 & 0 & $\begin{array}{c}1 \\
(10.00) \\
\end{array}$ \\
\hline Hold breath for at least 10 seconds* & $\begin{array}{c}16 \\
(22.20) \\
\end{array}$ & $\begin{array}{c}2 \\
(9.50) \\
\end{array}$ & 0 & 0 & $\begin{array}{c}2 \\
(22.20) \\
\end{array}$ & 0 & 0 & 0 & $\begin{array}{c}7 \\
(30.40) \\
\end{array}$ & $\begin{array}{c}2 \\
(20.00) \\
\end{array}$ \\
\hline Breath out gently (away from mouthpiece) & 0 & 0 & $\begin{array}{c}13 \\
(31.00) \\
\end{array}$ & $\begin{array}{c}2 \\
(22.20) \\
\end{array}$ & $\begin{array}{c}3 \\
(33.30) \\
\end{array}$ & 0 & $17(22.70)$ & $\begin{array}{c}4 \\
(17.40) \\
\end{array}$ & $\begin{array}{c}5^{\mathrm{c}} \\
21.70) \\
\end{array}$ & $\begin{array}{c}7^{\mathrm{c}} \\
(70.00) \\
\end{array}$ \\
\hline $\begin{array}{l}\text { If an extra dose is needed, wait } 1 \text { minute and then } \\
\text { repeat steps }\end{array}$ & $\begin{array}{c}36 \\
(50.00) \\
\end{array}$ & $\begin{array}{c}13 \\
(61.90) \\
\end{array}$ & 0 & 0 & $\begin{array}{c}8 \\
(88.90) \\
\end{array}$ & 0 & $48(64.00)$ & $\begin{array}{c}15 \\
(65.20) \\
\end{array}$ & $\begin{array}{c}11 \\
(47.80) \\
\end{array}$ & $\begin{array}{c}8 \\
(80.00) \\
\end{array}$ \\
\hline $\begin{array}{l}\text { Rinse your mouth with water after each use of } \\
\text { the inhaled steroids* }\end{array}$ & 0 & $\begin{array}{c}2 \\
(66.70) \\
\end{array}$ & 0 & 0 & $\begin{array}{c}3 \\
(33.30) \\
\end{array}$ & 0 & $\begin{array}{c}9 \\
(12.00) \\
\end{array}$ & $\begin{array}{c}1 \\
(4.30) \\
\end{array}$ & 0 & 0 \\
\hline
\end{tabular}

${ }^{\mathrm{a}} \mathrm{p}=0.035,{ }^{\mathrm{b}} \mathrm{p}=0.008,{ }^{\mathrm{c}} \mathrm{p}=0.016{ }^{*}$ critical step, NA=not applicable.

\section{DISCUSSION}

Most of COPD patients in this study were elderly with low education level and income similar to global report (Bousquet and Khaltaev, 2007). Proportion of patients performing at least 1 error $(85.31 \%)$ was higher than previous studies $(74.80 \%)$ (Pothirat et al., 2015) due to higher proportion of patients with multiple devices in this study $(78.40 \%$ vs $69.90 \%)$ (Pothirat et al., 2015). Proportion of patients performing at least 1 critical error and having history of exacerbation $(59.3 \%)$ was not different to the hospitalized patients $(59.0 \%)$ in previous study (Batterink et al., 2012). Patients performing at least 1 critical error possess the high risk of re-exacerbation since at least 1 critical error was associated with $50 \%$ increment of hospitalization or emergency department visit (Price, 2014).

The highest proportion of patients with at least 1 error and critical error were found in those using turbuhaler similar to previous study (Sriram and Percival, 2015). The pMDI without spacer was the most common device prescribed in this study supported previous studies (Batterink et al., 2012; Pothirat et al., 2015). It was associated with the utmost error among hospitalized patients (Batterink et al., 2012) while spacer enhanced its correct technique in patients with exacerbation (Pothirat et al., 2015). This study showed that history of exacerbation significantly reduced critical errors of pMDI without spacer though it is quite difficult to use, requires good hand-breath coordination and hand or finger 
muscle strength (Yawn et al., 2012). Short acting bronchodilator, one of the recommended management and prevention of severe exacerbation (Criner, 2015) is commercially available in pMDI then it is the crucial target for technique trainings and evaluation.

The intensive and repeated training during hospitalization can promote the correct technique. Moreover, exacerbation significantly increased adherence to the devices especially, the one relieving breathlessness (Wisniewski et al., 2014). On the other hand, the errors of other devices could not decrease since many risk factors of technique errors: old age with poor recognition, low education, multiple medications and devices (Bonini and Usmani, 2015, Micallef, 2015) were common in our patients. Furthermore, insufficient knowledge of inhaler techniques (Baverstock, Woodhall, and Maarman, 2010) and lack of attention in teaching and checking inhaler techniques (Anonyms, 2012) among health care professionals in the real clinical practice may involve these errors.

Several methods are strongly recommended for improving inhaler technique. Firstly, individualizing inhaler choice regarding patient's physical ability was shown to enhance good inhaler techniques (Chorao et al., 2014). Secondly, demonstration was proved to be better than verbal and written instructions (Yawn et al., 2012, Capstick and Clifton, 2012). The "teach back method" or patients' showing their inhaler techniques was strongly recommended (Dantic, 2013). Inhaler training aids should be used to assist training and assess techniques to ensure significant lung deposition (Capstick and Clifton, 2012). Thirdly, inhaler technique training is the continuous process. It is not time consuming since it can be as short as a few minutes with regular training (Capstick and Clifton, 2012). Lastly, the transitional care either different locations or different levels of care in the same location must be well established.

COPD patients with acute exacerbation showed no improvement in quality of life in the first 10 days after treatment and at 6 month after acute exacerbation, half of them even rated their health status as fair to poor and required carers for daily activities (Anzueto, 2010). Moreover, quality of life decreased significantly (Agrawal et al., 2015; Prakash et al., 2014) while risk of exacerbation increased significantly in severe and very severe COPD (Roisin and Vestbo, 2013). In this study, the mean time after acute exacerbation was 5.3 months and $70.30 \%$ of patients in exacerbation group were classified as severe and very severe COPD. Therefore, these patients were most likely to have poor quality of life and high risk of re-exacerbation. In addition, proportion of patients using multiple devices as well as costly inhaled therapy such as long acting $\mathrm{B}_{2}$ agonists and corticosteroids was significantly higher in exacerbation group. Thus these patients were strongly associated with high socioeconomic burden supported previous studies (Anzueto, 2010). Correct inhaler technique can ameliorate those problems. However, this study has some limitations. The errors of inhaler technique may be underestimated since some steps were difficult to evaluate through observation.

\section{CONCLUSION}

History of exacerbation has no impact on inhaler technique except for MDI without spacer. Inhaler technique training and assessment are strongly recommended to continue throughout the period of inhalation therapy. Improving inhaler technique can further decrease exacerbation rate as well as increase patients' quality of life and economic benefits.

\section{ACKNOWLEDGEMENT}

We would like to express special thank to Dr. Arthit Ourairat, President of Rangsit University. We also thank Dr. Charoen Chuchottaworn and Mrs. Ponglada Srivicha for their support on this study.

\section{Financial support and sponsorship: Nil.}

Conflict of Interests: The authors' declare no conflict of interest.

\section{REFERENCES}

Agh T, Meszaros A. 2012. Adherence to Therapy in Chronic Obstructive Pulmonary Disease: In: Ong KC, ed. Chronic Obstructive Pulmonary Disease - Current Concepts and Practice. Shanghai: InTech 275-290

Ahmad H, Farooqi R, Ashraf S, Afridi MZ. Assessment of inhaler technique of patients admitted with acute exacerbation of chronic obstructive pulmonary disease at pulmonology unit khyber teaching hospital, peshawar. KJMS, 2013; 6:230-233.

Agrawal S, Joshi R, Jain A. Correlation of severity of chronic obstructive pulmonary disease with health-related quality of life and sixminute walk test in a rural hospital of central India. Lung India, 2015; 32:233-40

Allen SC. Competence thresholds for the use of inhalers in people with dementia. Age Ageing, 1997; 26:83-6.

Anzueto A. Impact of exacerbations on COPD. Eur Respir Rev, 2010; 19:113-118.

Batterink J, Karen D, Amneet A, Carmen R. Evaluation of the Use of Inhaled Medications by Hospital Inpatients with Chronic Obstructive Pulmonary Disease. CJHP, 2012; 65:111-118.

Baverstock M, Woodhall N, Maarman V. Do healthcare professionals have sufficient knowledge of inhaler techniques in order to educate their patients effectively in their use?. Thorax, 2010; 65:117-118.

Bollu V, Ejzykowicz F, Rajagopalan K, Karafilidis J, Hay JW. Risk of all-cause hospitalization in COPD patients initiating long-acting or short-acting beta agonist therapy. J Med Econ, 2013; 16:1082-1088.

Bonini M, Usmani OS. The importance of inhaler devices in the treatment of COPD. COPD Research and Practice, 2015; 1:1-9.

Bousquet J, Khaltaev N. 2007. Global surveillance, prevention and control of chronic respiratory diseases, A comprehensive approach. Switzerland: World Health Organization.

Capstick TG, Clifton IJ. Inhaler Technique and Training in People With Chronic Obstructive Pulmonary Disease and Asthma: Inhaler Technique Training. Expert Rev Resp Med, 2012; 6:91-103.

Chorao P, Pereira AM, Fonseca JA. Inhaler devices in asthma and COPD--an assessment of inhaler technique and patient preferences. Respir Med, 2014; 108:968-975.

Criner GJ, Bourbeau J, Diekemper RL, Ouellette DR, Goodridge D, Hernandez P, Curren K, Balter MS, Bhutani M, Camp PG, Celli BR, Dechman G, Dransfield MT, Fiel SB, Foreman MG, Hanania NA, Ireland BK, Marchetti N, Marciniuk DD, Mularski RA, Ornelas J, Road JD, Stickland MK. Prevention of acute exacerbations of COPD: 
American College of Chest Physicians and Canadian Thoracic Society Guideline. Chest, 2015; 147:894-942.

Dantic DE. A critical review of the effectiveness of 'teach-back' technique in teaching COPD patients self-management using respiratory inhalers. Health Educ J, 2013; 73:41-50.

Farkas J, Kadivec S, Kosnik M, Lainscak M. Effectiveness of discharge-coordinator intervention in patients with chronic obstructive pulmonary disease: study protocol of a randomized controlled clinical trial. Respir Med, 2011; 105:26-30.

Ho SF, O. Mahony MS, Steward JA, Breay P, Burr ML. 2004. Inhaler technique in older people in the community. Age Ageing, 2004; 33:185-188.

Melani AS, Bonavia M, Cilenti V, Cinti C, Lodi M, Martucci P, Serra M, Scichilone N, Sestini P, Aliani M, Neri M. Inhaler mishandling remains common in real life and is associated with reduced disease control. Respir Med, 2011; 105:930-938.

Micallef LA. A review of the metered dose inhaler technique in asthmatic and COPD patients. Malta Medical Journal, 2015; $22-28$

Anonyms. Improving inhaler technique - who needs teaching? Drug Ther Bull, 2012: 50:109.

Pothirat C, Chaiwong W, Phetsuk N, Pisalthanapuna S, Chetsadaphan N, Choomuang W. Evaluating inhaler use technique in COPD patients. Int J Chron Obstruct Pulmon Dis, 2015, 10:1291-1298.

Prakash B, Puri MM, Kumar L, Malik A, Behera D. Correlation of quality of life and activities of daily living with disease stage in patients with COPD. Int J Med. Public Health, 2014, 4:275-279.

Press VG, Arora VM, Shah LM, Lewis SL, Charbeneau J, Naureckas ET, Krishnan JA. Teaching the use of respiratory inhalers to hospitalized patients with asthma or COPD: a randomized trial. J Gen Intern Med, 2012; 27:1317-1325.
Price D. 2014. The Significance Of Inhaler Technique \& How To Improve It. [online] Available at: www.ondrugdelivery.com. [Accessed 20 April 2016].

Roisin RR, Vestbo J. 2013. Global initiative for chronic obstructive lung disease. Global strategy for the diagnosis, management, and prevention of chronic obstructive pulmonary disease.

Sriram KB, Percival M. Suboptimal inhaler medication adherence and incorrect technique are common among chronic obstructive pulmonary disease patients. Chronic Respiratory Disease, 2015:1-10.

Wisniewski D. Porzezinska M. Gruchala-Niedoszytko M, Niedoszytko M, Slominski JM, Jassem E. Factors influencing adherence to treatment in COPD patients and its relationship with disease exacerbations. Pneumonol Alergol Pol, 2014; 82:96-104.

Yawn BP, Colice GL, Hodder R. Practical aspects of inhaler use in the management of chronic obstructive pulmonary disease in the primary care setting. Int J Chron Obstruct Pulmon Dis, 2012; 7:495-502.

\section{How to cite this article:}

Duangrithi D, Saiprom K, Tew JS, Sa-u Y. Impact of exacerbation on the errors of inhaler techniques in COPD patients. J App Pharm Sci, 2017; 7 (05): 084-089. 